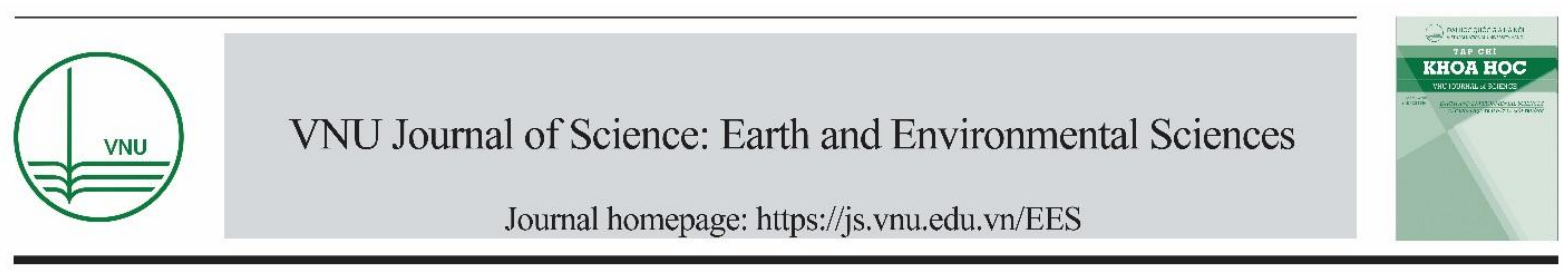

Original Article

\title{
Application of Seismuc Attribute Analysis to Reserch the Distribution of Middle Miocene Coral Reef Carbonate in Block 04-3, Nam Con Son Basin
}

\author{
Pham Bao Ngoc ${ }^{1}$, Tran Trung Dong ${ }^{2}$, Tran $\mathrm{Nghi}^{3}$, Nguyen Thi Phuong Thao ${ }^{3, *}$ \\ Tran Thi Oanh ${ }^{1}$, Pham Thi Thu Hang ${ }^{4}$, Bui Thi Ngan ${ }^{5}$ \\ ${ }^{1}$ Petrovietnam University, PVN, 762 Cach Mang Thang Tam, Long Toan, Ba Ria-Vung Tau, Vietnam \\ ${ }^{2}$ Science Research \& Engineering Institute, VSP, 105 Le Loi, Thang Nhi, Ba Ria-Vung Tau, Vietnam \\ ${ }^{3}$ VNU University of Science, 334 Nguyen Trai, Hanoi, Vietnam \\ ${ }^{4}$ Institute of Marine Geology and Geophysics, Vietnam Academy of Science and Technology, \\ 18 Hoang Quoc Viet, Nghia Do, Cau Giay, Ha Noi \\ ${ }^{5}$ Hanoi University of Mining and Geology, 18 Pho Vien, Duc Thang, Bac Tu Liem, Ha Noi
}

Received 15 June 2020

Revised 25 August 2020; Accepted 29 August 2020

\begin{abstract}
The seismic properties of Root Mean Square Amplitude, Maximum Amplitude, and Sum of Positive Amplitude most clearly reflect the distribution characteristics of middle Miocene carbonate sediments in block 04-3, Nam Con Son basin. Middle Miocene carbonate is commonly distributed on both reflection surfaces of $\mathrm{P} 1$ and P2. Within each reflective surface, carbonate sediments are concentrated around the uplifting zones, such as structures of Thien Ung - Mang Cau, Dai Hung and Bo Cau. These are completely consistent with the results of the interpretation of well$\log$ data of Vietsovpetro, VSP [1]. The wells C-2X and C-4X located at the edge of the uplifting zone should have the thickest carbonates. According to the results of amplitude attribute analysis, these wells are distributed in the high concentration area of carbonate formations. Meanwhile well $\mathrm{C}-1 \mathrm{X}$ and well C-3X, which are near the top of the uplifting zone and further away from the uplifting structure have thin carbonate set and belongs to a low carbonate density area.
\end{abstract}

Keywords: Seismic attribute, middle Miocene carbonate, acoustic impedance, reef carbonate, block 04-3, Nam Con Son basin.

\footnotetext{
* Corresponding author.

E-mail address: phuongthao298@gmail.com

https://doi.org/10.25073/2588-1094/vnuees.4647
} 


\title{
Đặc điểm phân bố trầm tích cacbonat ám tiêu Miocen giữa, Lô 04-3, bể Nam Côn Sơn trên cơ sở phân tích thuộc tính địa chấn
}

\author{
Phạm Bảo Ngọc ${ }^{1}$, Trần Trung Đồng ${ }^{2}$, Trần $\mathrm{Nghi}^{3}$, Nguyen Thi Phuong Thao $^{3, *}$ \\ Trần Thị Oanh ${ }^{1}$, Phạm Thị Thu Hằng ${ }^{4}$, Bùi Thị Ngân ${ }^{5}$ \\ ${ }^{I}$ Truờng Đại học Dầu khí Việt Nam, Số 762 Cách Mạng Tháng Tám, Long Toàn, Bà Rịa-Vũng Tàu, Việt Nam \\ ${ }^{2}$ Viện Nghiên cứu khoa học và thiết kế Dầu khí biển, VSP, Số 105 Lê Lợi, Thắng Nhì, Bà Rịa-Vũng Tàu, Việt Nam \\ ${ }^{3}$ Truò̀ng Đại học Khoa học Tụ nhiên, ĐHQGHN, 334 Nguyễn Trãi, Hà Nội, Việt Nam \\ ${ }^{4}$ Viện Địa chất - Địa vật lý Biển, Viện Hàn lâm Khoa học và Công nghệ Việt Nam \\ 18 Hoàng Quốc Việt, Nghĩa Đô, Cầu Giấy, Hà Nội \\ ${ }^{5}$ Truờng Đại học Mỏ Địa chất Hà Nội, Số 18 Phố Viên, Đức Thắng, Bắc Tù Liêm, Hà Nội \\ Nhận ngày 15 tháng 6 năm 2020 \\ Chỉnh sửa ngày 25 tháng 8 năm 2020; Chấp nhận đăng ngày 29 tháng 8 năm 2020
}

\begin{abstract}
Tóm tắt: Thuộc tính địa chấn biên độ trung bình bình phương (Root Mean Square Amplitude), biên độ cực đại (Maximum Amplitude), và tổng biên độ dương (Sum of Positive Amplitude) phản ảnh đặc điểm phân bố của trầm tích cacbonat ám tiêu Miocen giữa, khu vực lô 04-3, bể Nam Côn Sơn một cách rõ rệt nhất. Cacbonat Miocen giữa phân bố phổ biến ở hai mặt phản xạ P1và P2, trong phạm vi mỗi mặt phản xạ, trầm tích cacbonat tập trung ở xung quanh các đới nâng, điển hình như các cấu tạo Thiên Ung - Mãng Cầu, Đại Hùng và Bồ Câu. Kết quả này hoàn toàn phù hợp với kết quả minh giải tài liệu địa vật lý giếng khoan của Viện Nghiên cứu khoa học và thiết kế Dầu khí biển, VSP [1]. Các giếng $\mathrm{C}-2 \mathrm{X}$ và $\mathrm{C}-4 \mathrm{X}$ ở rìa đới nâng nên có các tập cacbonat dày hơn cả. Theo kết quả phân tích thuộc tính biên độ các giếng khoan này phân bố ở khu vực tập trung cao các thực thể cacbonat. Trong khi đó, giếng $\mathrm{C}-1 \mathrm{X}$ nằm ở gần đỉnh đới nâng và $\mathrm{C}-3 \mathrm{X}$ nằm khá xa đới nâng hơn thì các tập cacbonat mỏng và thuộc khu vực mật độ cacbonat thấp.
\end{abstract}

Từ khoá: Thuộc tính địa chấn, cacbonat Miocen giữa, cacbonat ám tiêu, lô 04-3, bể Nam Côn Sơn.

\section{Mở đầu}

Lô 04-3 thuộc phạm vi bể trầm tích Nam Côn Sơn, bao gồm một số cấu tạo điển hình như Đại Bàng-Ưng Trắng, Đại Hùng, Mãng Cầu-Thiền Ung, Bồ Câu, Hoàng Hạc, Hải Âu. Khu vực nghiên cứu cách thành phố Vũng Tàu khoảng $300 \mathrm{~km}$ về phía Đông Nam (Hình 1). Bể Nam Côn Sơn nói chung và lô $04-3$ nói riêng là khu vực tìm kiếm thăm dò và khai thác dầu khí quan

\footnotetext{
* Tác giả liên hệ.

Địa chỉ email: phuongthao298@gmail.com

https://doi.org/10.25073/2588-1094/vnuees.4647
}

trọng của Tập đoàn Dầu khí Việt Nam [1-4]. Bể Nam Côn Sơn được hình thành theo cơ chế tách giãn, trải qua lịch sử hình thành và phát triển địa chất khá phức tạp, thể hiện qua các đặc trưng cấu trúc địa chất cũng như đặc điểm thạch học của bể [4-6].

Đặc điểm trầm tích là một trong những cơ sở khoa học quan trọng để phân tích, đánh giá các yếu tố trong hệ thống dầu khí. Do đó, trầm tích Miocen giữa của bể Nam Cơn Sơn đã được nhiều 
công trình nghiên cứu đề cập đến, điển hình gồm những nghiên cứu về đặc điểm địa chất, thạch học, môi trường trầm tích và địa tầng phân tập [7-11]. Tuy nhiên, còn ít công trình nghiên cứu tập trung vào đối tượng cacbonat ám tiêu, trong khi đây là kiểu trầm tích khá phổ biến và có ý nghĩa dầu khí trong khu vực trung tâm bể Nam Côn Sơn.

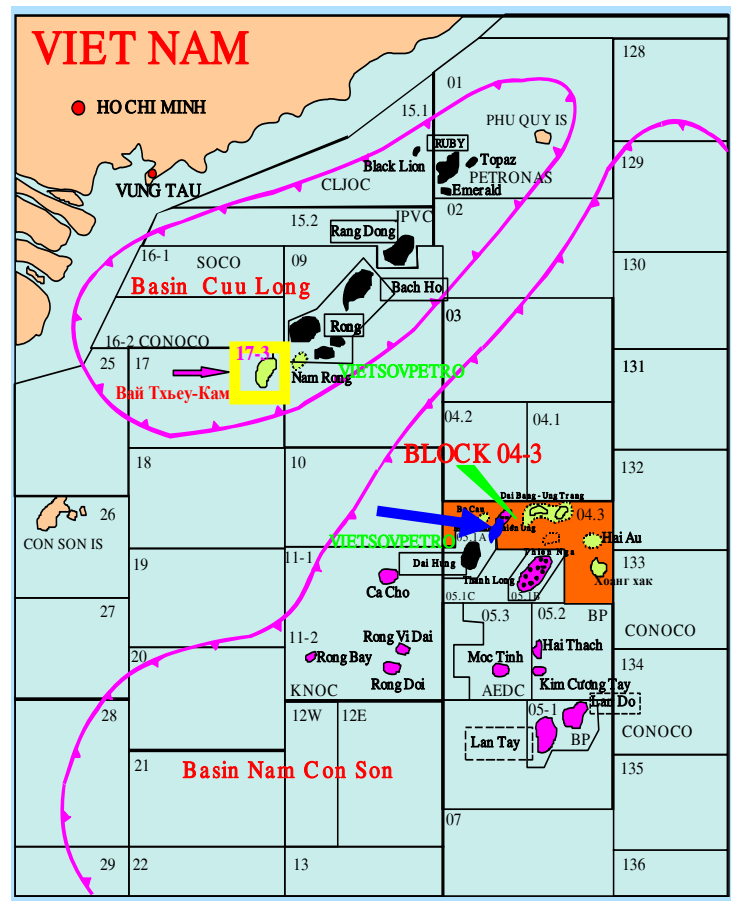

Hình 1. Sơ đồ khu vực lô 04-3, bể Nam Côn Sơn [1].

Công tác tìm kiếm thăm dò dầu khí tại lô 04 3 được bắt đầu từ những năm 70 của thế kỉ $\mathrm{XX}$ [2]. Đến nay, đã phát hiện thân dầu ở khối nâng của cấu tạo Đại Bàng, Đại Hùng; một loạt thân dầu, khí - condensat ở cấu tạo Thiên U’ng Mãng Cầu và cấu tạo này được công bố phát hiện thương mại vào năm 2009 [1,2]. Trong số các đối tượng chứa dầu, khí thuộc phạm vi lô 04-3 phải kề đến các đá cacbonat ám tiêu nứt nẻ tuổi Miocen giữa. Do đó, việc nghiên cứu sự phân bố của loại hình trầm tích cacbonat này có ý nghĩa quan trọng trong việc khoanh vùng triển vọng dầu khí cho khu vực. Tuy nhiên, khu vực nghiên cứu thuộc bể trầm tích nước sâu, xa bờ; đối tượng nghiên cứu là trầm tích cacbonat Miocen giữa nên các phương pháp địa chất truyền thống gặp nhiều hạn chế. Trong khi đó, tài liệu địa chấn hiện nay có chất lượng tốt, liên tục trên diện rộng, rất thuận lợi cho công tác minh giải cả đặc điểm cấu trúc lẫn đặc điểm thạch học cũng như môi trường trầm tích. Vì vậy, nhóm tác giả đã áp dụng phương pháp phân tích thuộc tính địa chấn nhằm làm rõ quy luật phân bố và ranh giới địa tầng của đá cacbonat ám tiêu trong phạm vi lô 04-3.

\section{Cơ sở dữ liệu và phương pháp nghiên cứu}

\subsection{Cơ sở dũ liệu}

Cơ sở dữ liệu của nghiên cứu bao gồm các tài liệu địa chất và địa vật lý ở bể Nam Côn Sơn nói chung và khu vực lô 04-3 nói riêng. Cụ thể, nhóm tác giả đã sử dụng tài liệu cube địa chấn 3D đã dịch chuyển chiều sâu trước công (PreStack Depth Migration- PSDM) bao phủ lô 04-3, đây là tài liệu địa chấn theo miền chiều sâu, được thu nổ năm 2007. Tài liệu địa chấn này là dữ liệu đầu vào quan trọng nhất nhằm minh giải các mặt phản xạ chính và phân tích thuộc tính địa chấn. Ngoài ra, bài báo còn sử dụng tài liệu minh giải địa vật lý giếng khoan của 4 giếng khoan C$1 \mathrm{X}, \mathrm{C}-2 \mathrm{X}, \mathrm{C}-3 \mathrm{X}$ và $\mathrm{C}-4 \mathrm{X}$, nằm trong phạm vi nghiên cứu.

\subsection{Phương pháp nghiên cứu}

Trong khuôn khổ bài báo, nhóm tác giả sử dụng (1) phương pháp phân tích thuộc tính địa chấn thông qua phần mềm Petrel của Công ty Dầu khí quốc tế Schlumberger và (2) phương pháp liên kết địa tầng và đối sánh với tài liệu địa vật lý giếng khoan.

Thuộc tính địa chấn (seismic attributes) là tất cả các đặc điểm của trường sóng như hình dạng, biên độ, tần số, tốc độ truyền sóng phản xạ... Đối với mỗi kiểu trầm tích khác nhau sẽ phản ánh những đặc trưng trường sóng địa chấn khác nhau do đặc điểm thành phần thạch học khác nhau. Nghiên cứu tập trung vào thuộc tính biên độ để phân tích những điểm dị thường nhằm khoanh vùng phân bố đá cacbonat ám tiêu trong khu vực nghiên cứu. 
Dựa vào đặc trưng động học của phản xạ địa chấn, bài báo sẽ phân tích các thuộc tính địa chấn nhằm dự báo sự phân bố cacbonat ám tiêu trong Miocen giữa.Thuộc tính địa chấn là một phép đo bất kỳ của tài liệu địa chấn để nâng cao khả năng hiển thị, định lượng các yếu tố địa chất hoặc thuộc tính đá chứa nhằm xác định cấu trúc hoặc môi trường lắng đọng trầm tích và nội suy các thuộc tính khác. Nhìn chung, có 02 loại thuộc tính gồm thuộc tính khối và thuộc tính bề mặt nhưng chúng đều chứa các thông tin địa chất cần minh giải:

Thuộc tính bề mặt: xuất ra các thuộc tính theo bề mặt khỏi các khối tài liệu dựa trên sự phân tích "hình dạng tín hiệu".

Thuộc tính khối: dựa trên các thuộc tính khác nhau của "tính hiệu tương tự", thuộc tính khối tạo ra các khối tài liệu được hiện thực hóa (realized) về mặt vật lý hoặc tài liệu ảo (virtual) đối với tài liệu địa chấn nhập vào.

Quá trình trích xuất thuộc tính địa chấn khối hoặc thuộc tính bề mặt được thực hiện theo khoảng cửa sổ mà trong đó các giá trị thông số được chọn phù hợp để phát hiện ra các sự kiện địa chấn của đối tượng quan tâm. Thay đổi các giá trị trên của cửa sồ nghiên cứu để đánh giá mức độ phù hợp giữa thuộc tính địa chấn với kết quả minh giải địa vật lý giếng khoan...

Nhóm thuộc tính địa chấn theo bề mặt bao gồm các thuộc tính sau:

- Biên độ trung bình bình phương (Root Mean Square Amplitude - RMS): được tính bằng căn bậc hai của giá trị trung bình bình phương từng biên độ tức thời trên một cửa sổ ấn định;

- Biên độ dương cực đại (maximum positive amplitude);

- Biên độ âm cực đại (maximum negative amplitude);

- Tổng biên độ dương (sum of positive amplitudes);

- Tổng biên độ âm (sum of negative amplitudes);

- Tổng biện độ (sum of magnitude);

- Biên độ trung bình (average magnitude);
- Trở kháng âm học tương đối (relative acoustic impedance);

- Tỷ số biên độ dương/âm (ratio of positive to negative) là tỷ số giữa số lượng giá trị biên độ dương trên số lượng giá trị biên độ âm trong một khoảng đo. Nếu không có giá trị âm trong khoảng đo, giá trị này mặc định là 0 .

Nhóm thuộc tính địa chấn theo khối gồm các thuộc tính sau:

Biên độ bình phương trung bình - Root Mean Square Amplitude (RMS) là một trong những thuộc tính địa chấn cơ bản của các mạch địa chấn, trên mạch địa chấn tức thời được lấy mẫu trên một cửa sổ nhất định. Một thông số chiều dài của cửa sổ được xác định bởi một số lượng các mẫu (mặc định là 9 mẫu). Phương pháp này được áp dụng khi xử lý và minh giải tài liệu địa chấn để xác định và dự báo sự phân bố các đặc trưng địa chất, địa tầng, cấu trúc và đặc trưng đá chứa, hệ thống đứt gãy của các tầng minh giải. Cụ thể, sử dụng công thức phân tích giá trị biên độ trong cửa sổ định sẵn nhằm tính bề dày tổng, độ rỗng tổng; xác định các tầng chứa dầu, kênh rạch, bồi tích, tập cacbonat, bề mặt bất chỉnh hợp, thay đổi địa tầng trầm tích như bên dưới:

Biên độ bình phương trung bình

$$
=\sqrt{\frac{1}{N} \sum_{i=1}^{N} a_{i}^{2}}
$$

Biên độ trung bình tuyệt đối $=\frac{1}{N}=\sum_{i-1}^{N}\left|a_{i}\right|$

Trong đó: $\mathrm{N}$ : số mẫu biên độ trong cửa sổ phân tích; a: độ lớn biên độ

Bên cạnh thuộc tính RMS còn nhiều thuộc tính biên độ khác như thuộc tính biên độ tuyệt đối trung bình (Average Absolute Amplitude), thuộc tính biên độ dương trung bình (Average Peak Amplitude), thuộc tính biên độ âm trung bình (AverageTrough Amplitude) cũng có mục đích liên quan đến việc xác định dị thường biên độ của đối tượng cacbonat ám tiêu.

Ngoài phương pháp phân tích thuộc tính địa chấn nói trên, phương pháp liên kết địa tầng và đối sánh với tài liệu địa vật lý giếng khoan là một trong những phương pháp không thể thiếu trong 
việc chính xác hoá ranh giới và quy luật phân bố của trầm tích cacbonat ám tiêu. Dựa trên các kết quả minh giải về thạch học của các giếng khoan $\mathrm{C}-1 \mathrm{X}, \mathrm{C}-2 \mathrm{X}, \mathrm{C}-3 \mathrm{X}$ và $\mathrm{C}-4 \mathrm{X}[1,2,8]$ trong khu vực nghiên cứu, nhóm tác giả đã đối sánh với kết quả chạy thuộc tính theo từng ranh giới mặt phản xạ (theo không gian) và theo chiều sâu (theo thời gian).

\section{Kết quả phân tích thuộc tính địa chấn}

Trước tiên, nhóm tác giả tiến hành minh giải các mặt phản xạ chính trong phạm vi tầng Miocen giữa của khu vực nghiên cứu. Kết quả cho thấy, khoảng địa tầng Miocen giữa nằm trong giới hạn mặt phản xạ $\mathrm{B}$ đến mặt phản xạ $\mathrm{C}$, trong đó hai tầng phản xạ $\mathrm{P} 1$ và $\mathrm{P} 2$ có đặc điểm phản xạ mạnh, biên độ cao, pha sóng chạy liên tục (Bảng 1, Hình 2,3). Đối sánh với kết quả minh giải tài liệu địa vật lý giếng khoan $[1,2,8]$ và tài liệu phân tích mùn khoan của các giếng $\mathrm{C}$ $1 \mathrm{X}, \mathrm{C}-2 \mathrm{X}, \mathrm{C}-3 \mathrm{X}$ và $\mathrm{C}-4 \mathrm{X}$ cho thấy đây chính là các mặt phân bố trầm tích cacbonat. Trên cơ sở đó, nhóm tác giả tiếp tục chạy và lựa chọn thuộc tính trên hai mặt phản xạ này nhằm khoanh vùng phân bố của trầm tích cacbonat ám tiêu.

Bảng 1. Đặc điểm trường sóng của các mặt phản xạ $\mathrm{P} 1$ và $\mathrm{P} 2$ trong khu vực nghiên cứu

\begin{tabular}{|c|c|c|c|}
\hline Tầng & $\begin{array}{c}\text { Trở kháng } \\
\text { âm học }\end{array}$ & $\begin{array}{c}\text { Đường đặc trưng } \\
\text { địa chấn }\end{array}$ & Đặc điểm \\
\hline P1 & Tăng & Đỉnh (+) & $\begin{array}{c}\text { Biên độ cao, độ } \\
\text { liên tục tốt }\end{array}$ \\
\hline P2 & Tăng & Đỉnh (+) & $\begin{array}{c}\text { Biên độ cao, độ } \\
\text { liên tục tốt }\end{array}$ \\
\hline
\end{tabular}

Trong quá trình chạy các thuộc tính địa chấn cho đối tượng cacbonat, nhóm tác giả đã chạy lần lượt các thuộc tính địa chấn theo hai nhóm gồm nhóm thuộc tính địa chấn theo bề mặt (surface seismic attributes) và nhóm thuộc tính địa chấn theo khối (volume seismic attributes). Trên cơ sở kết quả thu được, nhóm tác giả lựa chọn các thuộc tính cho kết quả thể hiện rõ sự phân bố của đá cacbonat.
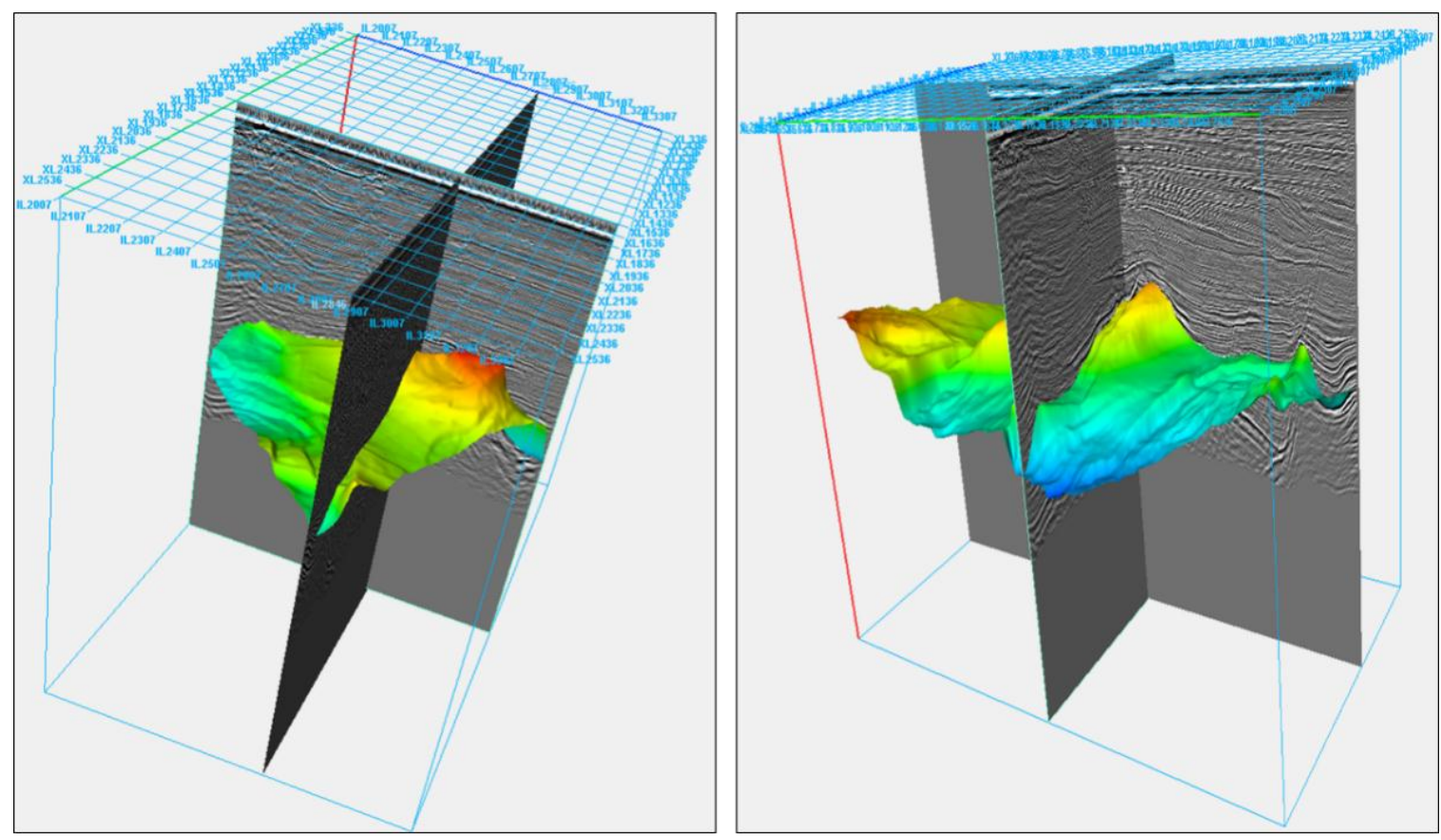

Hình 2. Mặt phản xạ P1 và P2 trong không gian ba chiều. 


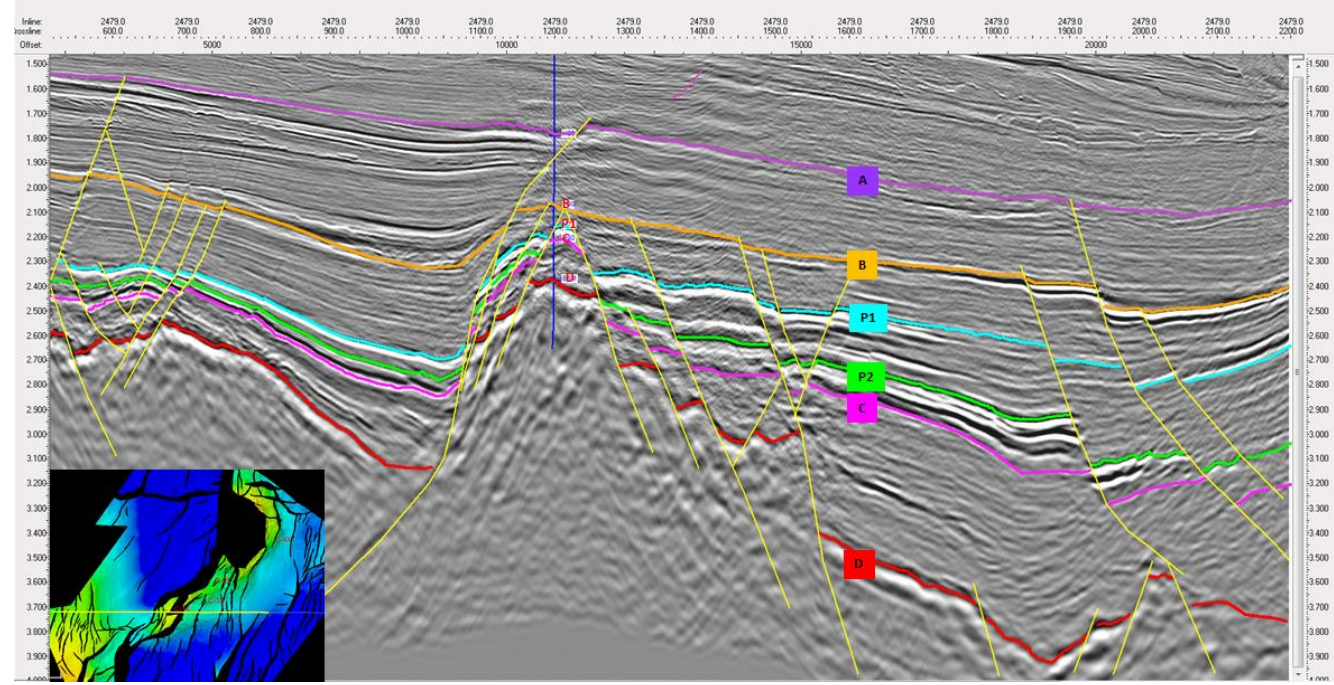

Hình 3. Mặt cắt địa chấn thể hiện các mặt phản xạ $\mathrm{B}, \mathrm{P} 1, \mathrm{P} 2$ và $\mathrm{C}$ trong phạm vi

khoảng địa tầng Miocen giữa; trong đó mặt phản xạ P1 và P2 chính là các bề mặt trầm tích cacbonat ám tiêu.

Phân tích các kết quả chạy các thuộc tính địa chấn bề mặt cho thấy, thuộc tính RMS, Maximum Ámplitude và Sum of Positive Amplitude thể hiện sự phân bố trầm tích cacbonat rõ nhất cho cả 2 mặt phản xạ chính P1 và $\mathrm{P} 2$ (Hình 4-6). Diện phân bố trầm tích này trên các bản đồ chính là các khu vực có màu vàng, xanh lá và xanh ngọc. Kết quả phân tích bằng thuộc tính RMS và Maximum Amplitude phản ánh khá rõ tầng cacbonat ở mặt phản xạ P1, trong khi mặt phản xạ $\mathrm{P} 2$ thể hiện trầm tích cacbonat ám tiêu tập trung tại khối nâng Trung tâm và phía Đông, giảm dần ở khu vực phía Tây. Quy luật phân bô này thể hiện rõ trên mặt cắt thuộc tính tương ứng.
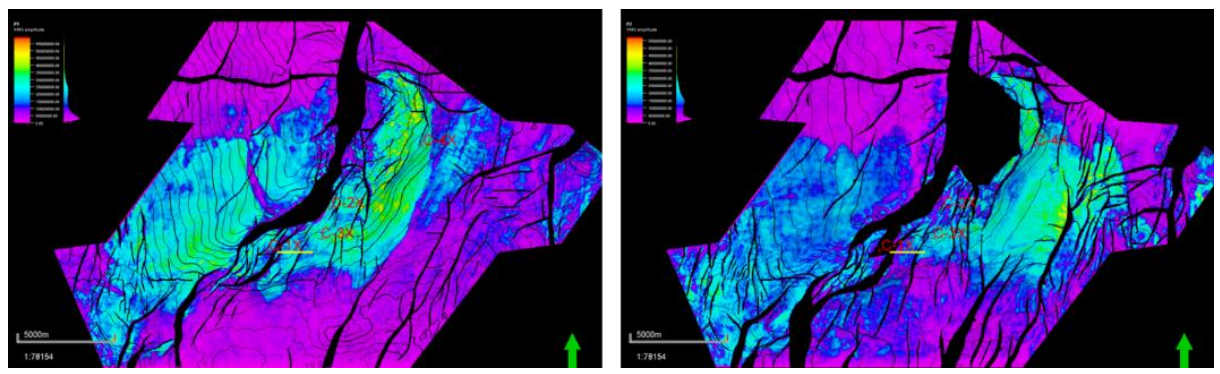

Hình 4. Sự phân bố trầm tích cacbonat ám tiêu trên các mặt phản xạ P1 (trái) và P2 (phải) bằng thuộc tính RMS.
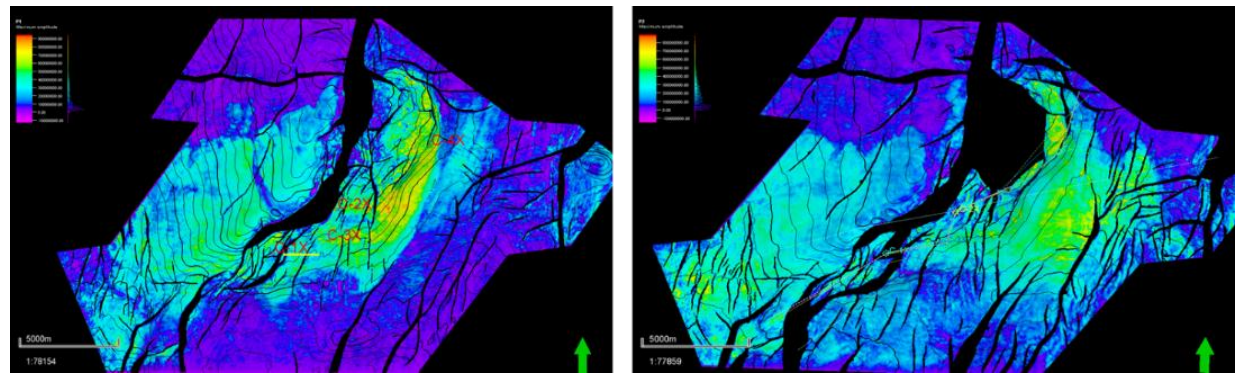

Hình 5. Sự phân bố trầm tích cacbonat ám tiêu trên các mặt phản xạ P1 (trái) và P2 (phải) bằng thuộc tính Maximum Amplitude. 

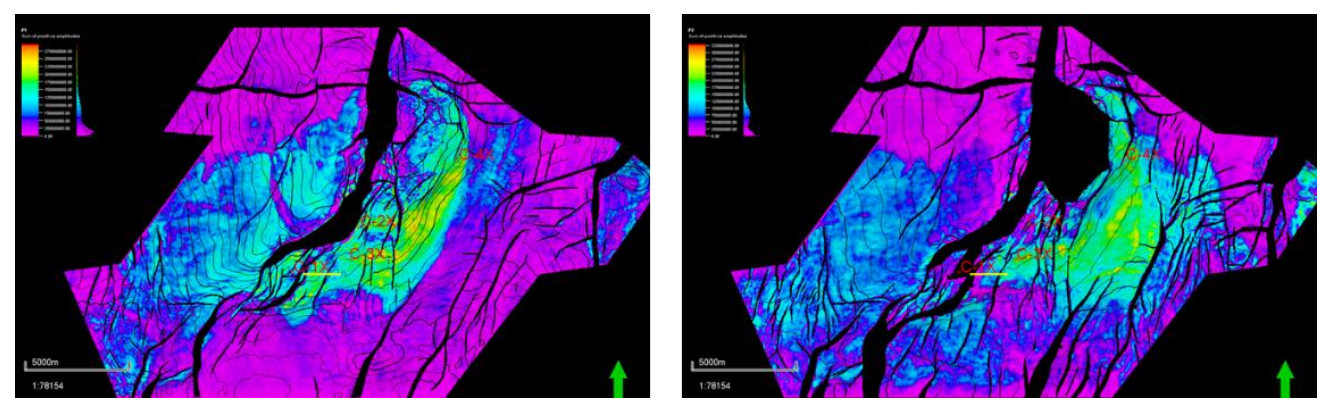

Hình 6. Sự phân bố trầm tích cacbonat ám tiêu trên các mặt phản xạ P1 (trái) và P2 (phải) bằng thuộc tính địa chấn tổng biên độ dương (Sum of Positive Amplitude).

Các sơ đồ dự báo sự phân bố của tập đá vôi P1 theo tài liệu thuộc tính địa chấn tổng biên độ dương (Hình 6) cho kết quả phù hợp với kết quả minh giải tài liệu địa vật lý giếng khoan (Hình 7). Cụ thể đặc điểm phân bố như sau: trầm tích cacbonat ám tiêu chủ yếu phân bố ở nóc tập tầng $\mathrm{P} 1$, phân bố xung quanh đới nâng trung tâm, và càng ra xa đới nâng thì diện phân bố giảm dần. Theo mặt cắt từ giếng khoan C-1X, C-2X, C-3X đến $\mathrm{C}-4 \mathrm{X}$ cho thấy rằng tập cacbonat có $\mathrm{xu}$ hướng dày lên đáng kể, từ $52 \mathrm{~m}$ tại giếng khoan $\mathrm{C}-1 \mathrm{X}$ đến $148 \mathrm{~m}$ tại giếng khoan C-4X. Điều này cũng phản ánh trên các mặt cắt thuộc tính địa chấn, khu vực có dị thường biên độ lớn chủ yếu tập trung tại khu vực giếng khoan $\mathrm{C}-2 \mathrm{X}$ và $\mathrm{C}$ $4 \mathrm{X}$.

Dựa trên kết quả phân tích tài liệu thuộc tính địa chấn cho thấy quy luật tương tự với đối tượng $\mathrm{P} 2$. Thuộc tính biên độ đa phần tập trung tại nóc vỉa và khu vực đới nâng trung tâm.

Mặt cắt liên kết giếng khoan cho thấy cacbonat ám tiêu chủ yếu phân bố ở nóc tầng P1, mỏng nhất ở giếng khoan $\mathrm{C}-1 \mathrm{X}$ và dày dần từ giếng khoan $\mathrm{C}-2 \mathrm{X}$ đến $\mathrm{C}-4 \mathrm{X}$ (tại giếng khoan $\mathrm{C}$ $1 \mathrm{X}$ là $52 \mathrm{~m}, \mathrm{C}-2 \mathrm{X} 112 \mathrm{~m}$ và $\mathrm{C}-4 \mathrm{X} 148 \mathrm{~m}$ ). Điều này khá phù hợp với xu hướng thay đổi của biên độ RMS cũng như tổng biên độ dương Sum of Positive Amplitudes (màu xanh ngọc từ giếng khoan $\mathrm{C}-1 \mathrm{X}$ đến màu xanh lá và vàng về phía $\mathrm{C}$ $4 \mathrm{X})$.

Tiếp theo, nhóm tác giả tiến hành phân tích thuộc tính khối, lựa chọn Time slice khác nhau trên tài liệu nhằm làm sáng tỏ sự phân bố và bề dày của trầm tích cacbonat ám tiêu (Hình 8).
Quan sát sơ đồ phân bố cacbonat cho tập P1-P2 theo thuộc tính RMS cho thấy khu vực khối nâng Trung Tâm cũng như cánh phía Tây của khối nâng Trung Tâm có biên độ RMS khá cao thể hiện bằng màu vàng trên bản đồ phân bố.

Dựa vào kết quả chạy thuộc tính RMS trên, nhóm tác giả tiếp tục tiến hành chạy thuộc tính RMS cho các cửa sổ khác nhau để nhận biết sự phân bố cacbonat theo chiều ngang (Hình 9). Kết quả chạy thuộc tính RMS cho từng lát cắt địa chấn (time slice) cho thấy cửa sổ time slice (dưới $280 \mathrm{~ms}$ ) và cửa số (dưới $1320 \mathrm{~ms}$ ) cho thấy biên độ RMS khá cao ở khối nâng Trung Tâm và cánh phía Tây của khối nâng do cửa sổ (dưới 280ms) khá gần với mặt phản xạ địa chấn $\mathrm{P} 1$. Tương tự với cửa sổ (dưới $1320 \mathrm{~ms}$ ) cũng khá gần với mặt phản xạ địa chấn $\mathrm{P} 2$.

Đối với 3 cửa sổ còn lại cho thấy sự phân dị biên độ RMS ở cánh phía Tây kém hơn so với khu vực khối nâng Trung Tâm. Kết quả trên cho thấy khá tương đồng với sự phân bố cacbonat ám tiêu của lô 04-3 theo kết quả minh giải tài liệu địa vật lý giếng khoan.

Mặt cắt thuộc tính RMS qua các giếng khoan $\mathrm{C}-1 \mathrm{X}, \mathrm{C}-3 \mathrm{X}, \mathrm{C}-2 \mathrm{X}$ và $\mathrm{C}-4 \mathrm{X}$ cho thấy các phản xạ biên độ cao tập trung chủ yếu ở phần trên của khối nâng Trung Tâm và cao nhất ở khu vực GK C-4X (Hình 10). Điều này khá phù hợp với kết quả đo địa vật lý giếng khoan. Cụ thể như khi đối sánh kết quả chạy thuộc tính địa chấn với tài liệu minh giải địa vật lý giếng khoan của GK C-4X cho thấy giá trị độ rỗng càng thấp thì biên độ càng cao và ngược lại (Hình 11). 


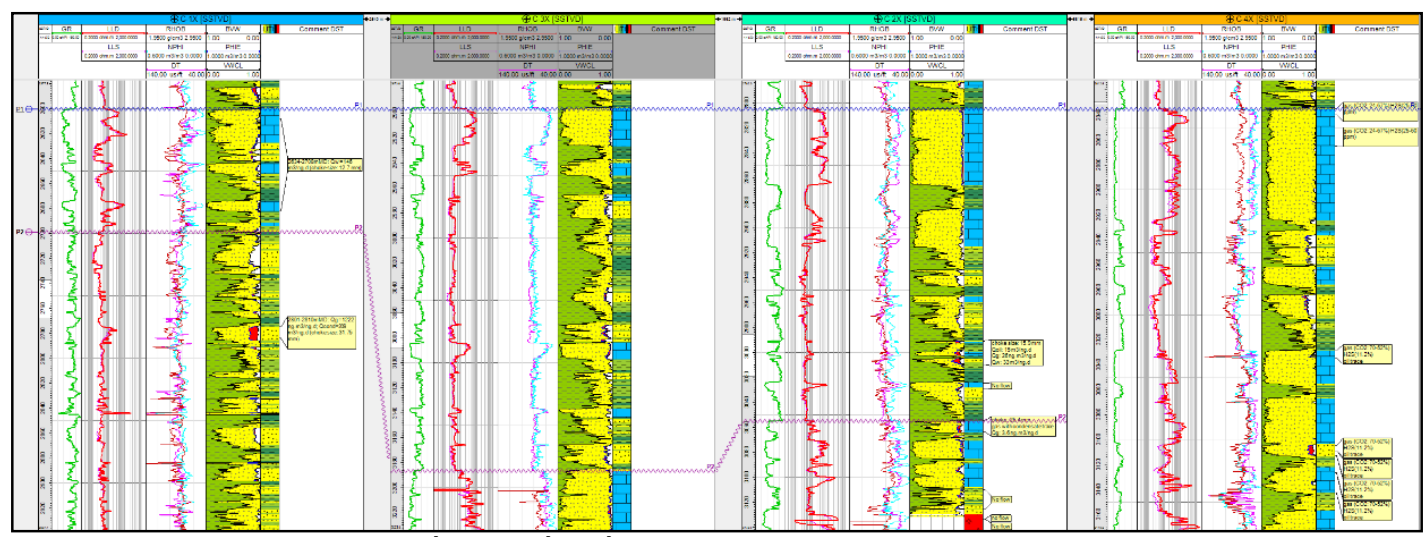

Hình 7. Mặt cắt liên kết giếng khoan C-1X, C 2X, C-3X và C-4X [1].

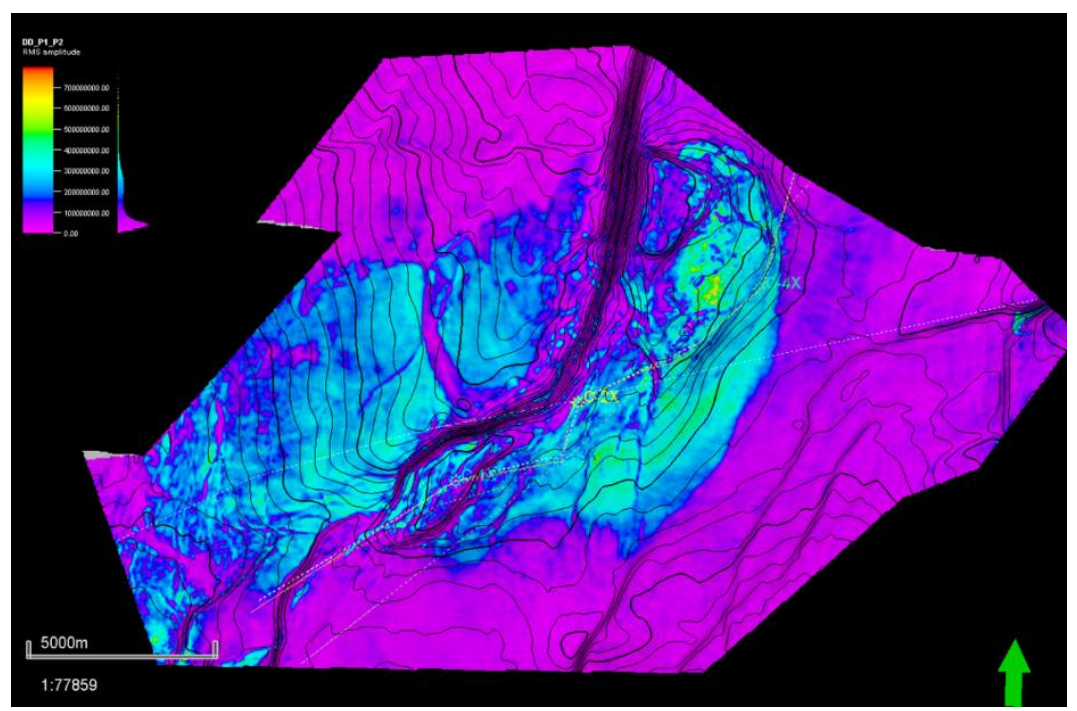

Hình 8. Sơ đồ phân bố cacbonat ám tiêu cho tập P1-P2 theo thuộc tính RMS.
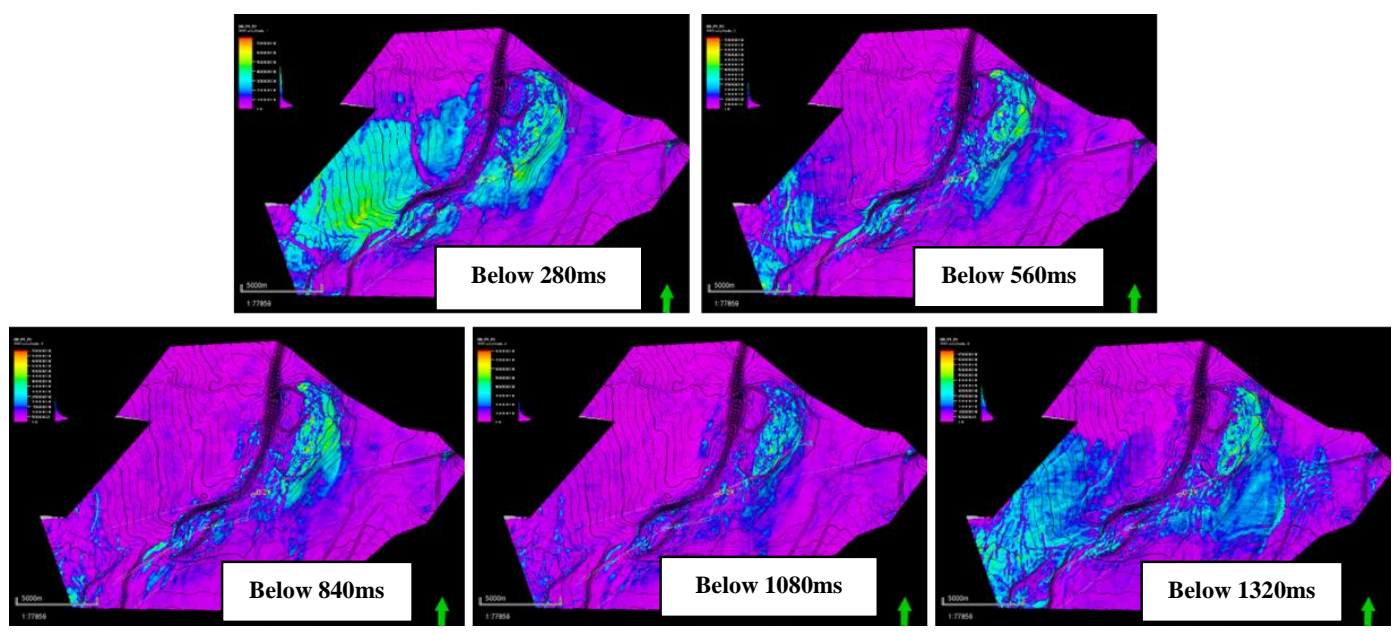

Hình 9. Sự phân bố trầm tích cacbonat ám tiêu theo time slice. 


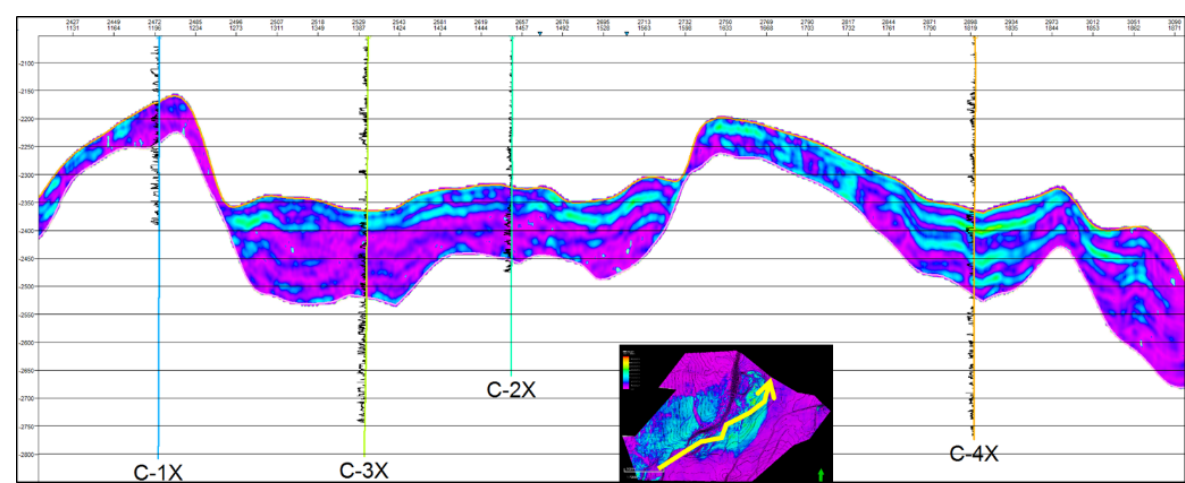

Hình 10. Liên kết mặt cắt địa chấn với các giếng khoan trong khu vực nghiên cứu.

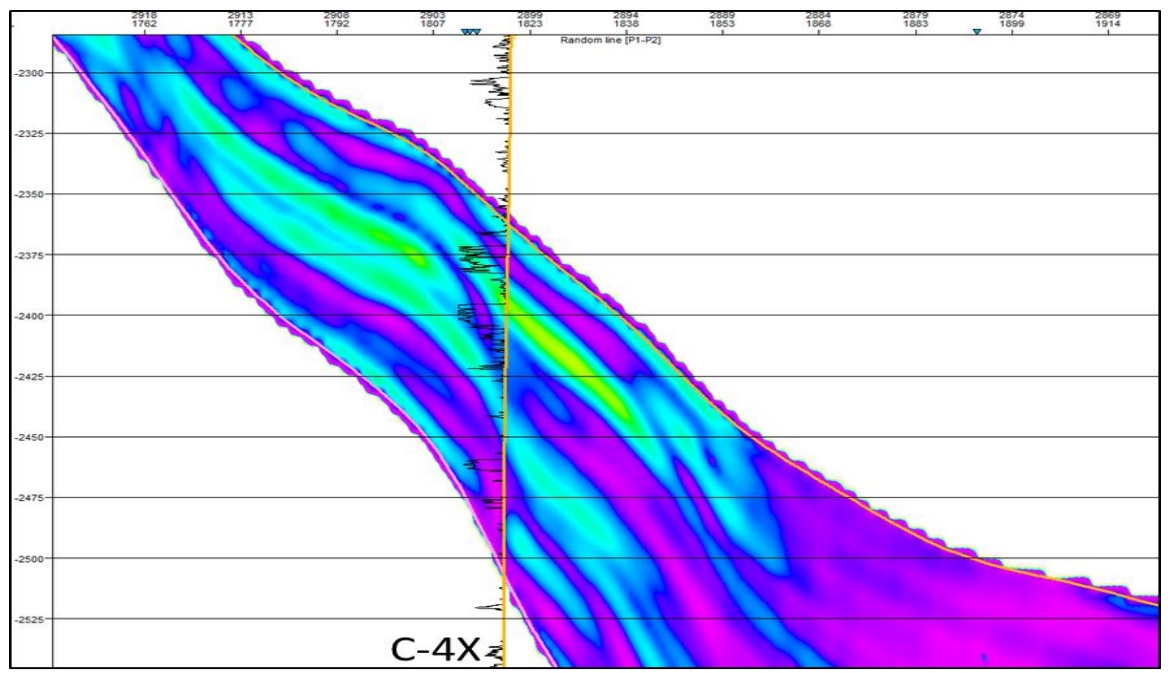

Hình 11. Mặt cắt thuộc tính RMS ngang qua giếng khoan C-4X.

\section{Thảo luận}

Các tập cacbonat trong khu vực nghiên cứu là một trong những đối tượng chứa dầu, khí cần được nghiên cứu cụ thể. Việc phân tích các thuộc tính địa chấn trên nhằm làm nổi bật diện phân bố của trầm tích cacbonat này có ý nghĩa quan trọng trong nghiên cứu, làm rõ đặc điểm cổ môi trường. Đặc biệt, cần tích hợp kết quả này của bài báo với các nghiên cứu về phân tích tướng, minh giải môi trường lắng đọng trầm tích xây dựng mô hình lắng đọng trầm tích trong khu vực nghiên cứu. Theo kết quả phân tích cổ sinh trong trầm tích Miocen giữa của VPI-Labs, tại một số giếng khoan trong khu vực phát hiện các tàn dư sinh vật như Formaminifera bám đáy và trôi nổi,
Tảo đỏ, Da gai, Ốc gai và các mảnh vỏ sinh vật $[12,13]$. Các bằng chứng này cho thấy trầm tích Miocen giữa được hình thành trong môi trường biển nông. Ngoài ra, kết quả nghiên cứu môi trường trầm tích khác cũng chỉ ra trầm tích Miocen giữa trong khu vực lô $04-3$ chủ yếu là môi trường biển nông trong thềm với sự có mặt của cacbonat ám tiêu san hô [14]. Trong khi đó, diện phân bố đá cacbonat theo kết quả phân tích thuộc tính địa chấn biên độ trung bình bình phương, biên độ cực đại và tổng biên độ dương đều chủ yếu tập trung xung quanh các cấu tạo nâng trong khu vực - nơi có độ sâu nước biển và nhiệt độ phù hợp cho các ám tiêu san hô phát triển. Điều này hoàn toàn phù hợp với các nguyên lý và quy luật trầm tích. 


\section{Kết luận}

1. Nhóm tác giả phân tích cả hai nhóm thuộc tính bề mặt và thuộc tính khối cho đối tượng cacbonat Miocen giữa của lô 04-3, bể Nam Côn Sơn; kết quả cho thấy thuộc tính Root Mean Square Amplitude, Maximum Amplitude và Sum of Positive Amplitudephản ảnh rõ nhất diện phân bố trầm tích cacbonat ám tiêu của khu vực nghiên cứu.

2. Trong khoảng địa tầng Miocen giữa, cacbonat ám tiêu phân bố tập trung ở hai mặt phản xạ $\mathrm{P} 1$ và $\mathrm{P} 2$. Ở mỗi mặt phản xạ, trầm tích này phân bố ở xung quanh các khu vực đới nâng như cấu tạo Thiên Ưng - Mãng Cầu, Đại Hùng và Bồ Câu.

3. Liên kết và đối sánh với tài liệu minh giải địa vật lý giếng khoan của các giếng trong khu vực nghiên cứu cho kết quả trùng khớp và phù hợp với các quy luật phân bố trầm tích, cụ thể các giếng $C-2 X$ và $C-4 X$ ở rìa đới nâng, có tập cacbonat ám tiêu dày hơn cả; trong khi giếng C$1 \mathrm{X}$ nằm ở gần đỉnh đới nâng và $\mathrm{C}-3 \mathrm{X}$ nằm khá xa đới nâng hơn thì có tập cacbonat ám tiêu mỏng.

\section{Lời cảm ơn}

Để hoàn thành được bài báo này, tập thể tác giả xin chân thành cảm ơn Trường Đại học Dầu khí Việt Nam đã tài trợ trong khuôn khổ đề tài mã số GV1904. Đồng thời, tác giả cũng gửi lời cảm ơn đến Viện Nghiên cứu Khoa học và Thiết kế Dầu khí biển đã tạo điều kiên tham khảo tài liệu quý báu trong quá trình thực hiện bài báo.

\section{Tài liệu tham khảo}

[1] Vietsovpetro (2014), Summary of data acquisition, processing and interpretation in geology and geophysics in the second phase and the exploration plan in the next phases, in Block 04-3 (in Vietnamese).

[2] Vietsovpetro (2011), Accuration of oil and gas reserves of Thien Ung - Mang Cau field, Block 043 until October $^{1 \mathrm{st}}, 2011$ (in Vietnamese).

[3] N. Hiep (2005), Geology and Petroleum Resources in Vietnam, Chapter 10 - Nam Con Son Basin and Petroleum Potential, Science and Technology Publishing (in Vietnamese).
[4] Vietnam Petroleum Institute (2012), Evaluation of Oil and Gas Potential in Nam Con Son Basin, Petroleum Archieve Center (in Vietnamese).

[5] L.C. Mai, N.H. Quynh, N.V. Linh, V.T.B. Ngoc, N.V. Vuong. Characteristics of Geological Structure of Nam Con Son Basin based on results of Seismic Interpretation, Journal of Petroleum 9 (2013) 16-25 (in Vietnamese).

[6] N.Q. Tuan, N.T. Tung, T.V. Tri, The Seismic Interpretation of Nam Con Son Basin and its Implication for the Tectonic Evolution. Indonesian Journal on Geoscience 3 (2)(2016) 127-137. https://doi.org/10.17014/ijog.3.2.127-137 .

[7] C.M.Hoang (2005), Geological Characteristics of Miocene Terrigenous Sediments in Nam Con Son Basin, Doctoral Thesis, Hanoi University of Mining and Geology (in Vietnamese).

[8] P.B. Ngoc (2019), Research on Depositional Environment Evaluation and Hydrocarbon Potential of Middle Miocene Formation in the center of the Nam Con Son Basin. Doctoral Thesis in Petroleum Engineering, Vietnam Petroleum Institute, 2019 (in Vietnamese).

[9] P.B. Ngoc, T. Nghi, N.T. Tin, T.V. Tri, N.T. Tuyen, T.T. Dung, N.T.P. Thao, Petrographic Characteristics and Depositional Environment Evolution of Middle Miocene Sediments in the Thien Ung Mang Cau Structure of Nam Con Son Basin. Indonesian Journal on Geoscience, 4 (3) (2017) 151-165. https://doi.org/10.17014/ijog.4.3.151-165.

[10] P.B. Ngoc, T. Nghi, Sequence Stratigraphy of Miocene Deposits in Nam Con Son Basin. VNU Journal of Science: Earth and Environmental Sciences 32(1) (2016) 36-44 (in Vietnamese).

[11] P.B. Ngoc, T. Nghi, N.T. Tin, The impacts of Petrophysical parameters on Petroleum Reservoir Potential of the Middle Miocene Sedimentary rock in the Thien Ung - Mang Cau Structure, Nam Con Son basin, VNU Journal of Science: Earth and Environmental Sciences 33(1) (2017) 52-64 (in Vietnamese).

[12] Vietnam Petroleum Institute (2005), Biostratigraphy of Well 04.3-TU-1X in Nam Con Son Basin, Petroleum Archieve Center (in Vietnamese).

[13] Vietnam Petroleum Institute (2006), Biostratigraphy of Well 04.3-TU-2X in Nam Con Son Basin, Petroleum Archieve Center (in Vietnamese).

[14] Vietnam Petroleum Institute (2012), Research on Sedimentary Environment, Paleontology and Seismic Stratatigraphy in order to determine the distribution of Reservoir Potential, in Block 04-3, Nam Con Son basin, Petroleum Archieve Center (in Vietnamese). 